\title{
Estatuto de Defesa do Torcedor: um diálogo com o futebol pelotense
}

\author{
Luis Carlos Rigo* \\ Alan Goulart Knuth"* \\ Luciano Jahnecka***
} Ricardo Prestes Tavares ${ }^{* * * *}$

Resumo: Este estudo objetiva analisar a situação dos estádios de futebol profissional de Pelotas, tendo como referência o Estatuto de Defesa do Torcedor (EDT), com atenção especial para as condições de higiene, segurança, ingressos e transporte. Como metodologia, além da análise documental do EDT realizamos visitas aos estádios em três momentos com registros fotográficos e entrevistamos um dirigente de cada clube: Grêmio Esportivo Brasil, Esporte Clube Pelotas e Grêmio Atlético Farroupilha. Constatamos que a atenção dedicada pela mídia e pelos órgãos fiscalizadores à implementação do EDT está sendo menor do que ocorreu no momento da sua publicação.

Palavras-chave: Futebol. Estatuto. Torcedor.

\section{Introdução}

Um dos argumentos mais utilizados pelas autoridades para justificar a importância da elaboração e implementação do Estatuto de Defesa do Torcedor (EDT) foi o de que ele seria uma peça fundamental para aperfeiçoar as práticas de sociabilidade que ocorrem nos espaços públicos e privados os quais aglutinam o público assistente (torcedores) das diferentes práticas esportivas. Na opinião dos autores o EDT, além de garantir melhores condições de higiene e segurança aos torcedores, constitui-se em uma medida, uma política pública, que poderia se contrapor à crescente onda de

Professor de graduação e pós-graduação na ESEF da UFPel. Doutor em Educação.

Bolsista PET/ESEF/UFPE

Bolsista Pibic, CNPa.

Acadêmico da ESEF/UFPEL.

Movimento, Porto Alegre, v.12, n. 02, p. 223-239, maio/agosto de 2006. 
violência que vem atingindo, desde o início dos anos 90, os estádios brasileiros de futebol. Apesar de não se restringir ao futebol, foi para ele que a maioria das considerações a respeito do EDT se voltaram. O EDT estaria adequado à realidade brasileira? Ele estaria em condições de ser posto em prática pela grande maioria dos clubes de futebol da primeira e segunda divisão? Ele está sendo capaz de inibir a onda de violência a qual vem atormentando os estádios brasileiros? A quem cabe a responsabilidade de fiscalizar a sua implementação? Essas são algumas interrogações colocadas desde o momento que o EDT foi promulgado.

Situado nesse contexto, posterior à publicação do EDT, o objetivo principal da realização desse estudo foi o de investigar como os clubes profissionais de futebol da cidade de Pelotas (Grêmio Esportivo Brasil, Esporte Clube Pelotas e Grêmio Atlético Farroupilha) estão implementando as diretrizes do EDT e até que ponto elas estão trazendo mudanças significativas principalmente no que tange à higiene, à segurança e ao conforto dos torcedores.

Mais do que verificar quais os artigos estão ou não sendo cumprindo por este ou aquele clube nosso estudo visa contribuir para melhorar as condições dos torcedores nos estádios de futebol, principalmente porque não nos conformamos com a idéia de que um esporte que, segundo declaração do Ministro do Esporte Agnelo Queiroz (Ministério do Esporte 2004), a cada final de semana entre jornalistas, atletas, dirigentes, árbitros e torcedores atinge aproximadamente 31 milhões de pessoas, é muito eficiente dentro de campo e movimenta anualmente milhões de dólares, deixe tanto a desejar quando se trata das condições que oferece para os torcedores.

A metodologia da pesquisa constitui-se de uma análise documental do EDT e da sua implementação junto aos clubes de futebol de Pelotas, realizamos duas visitas a cada um dos clubes, uma em março de 2004 e outra em outubro do mesmo ano, ocasião em que foram feitos

Movimento, Porto Alegre, v.12, n. 02, p. 223-239, maio/agosto de 2006. 
registros fotográficos ${ }^{1}$ sobre as condições dos banheiros, arquibancadas, corredores e gramado dos estádios e, por último, uma entrevista semi-estruturada nos moldes em que propõe Augusto Nibaldo Triviños (1987), com um dirigente de cada um dos clubes pesquisados.

\section{$2 \mathrm{~A}$ tradição do futebol pelotense}

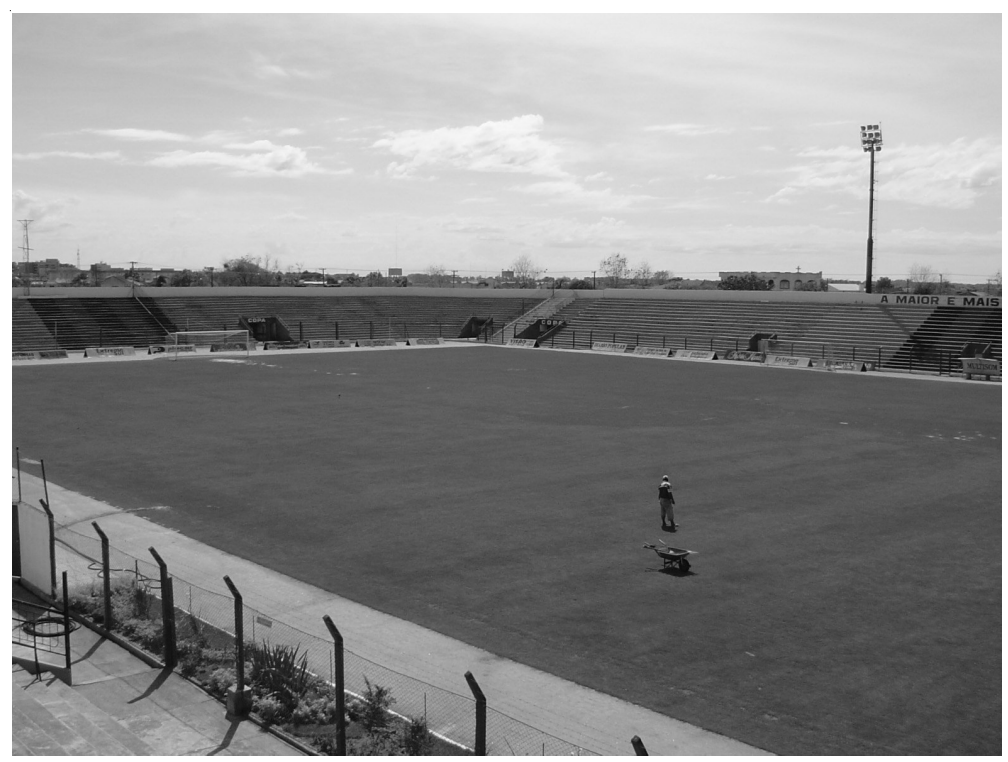

Figura 1: Vista geral do estádio Bento Freitas (G. E. Brasil). Foto: Ricardo Tavares.

Atualmente, existem em Pelotas três clubes profissionais de futebol: Grêmio Esportivo Brasil, fundado em 7 de setembro de 1911, cujo estádio é denominado de Bento Freitas e possui uma capacidade estimada em 18.000 pessoas; Esporte Clube Pelotas, fundado em 11 de outubro de 1908, proprietário do estádio Boca do Lobo que possui uma capacidade estimada em 15.000 pessoas, (em 2005 o estádio 1 O uso da fotografia com uma técnica capaz de auxiliar na coleta de dados para pesquisa
é uma estratégia que vem ganhando a cada dia uma maior aceitabilidade tanto no campo das Ciências Humanas, nas Ciências Biológicas e também nas Ciências Exatas. Maiores considerações sobre a sua utilização especificamente nas Ciências Humanas consultar: FELDMAN-BIANCO, Bele; LEITE, Mirian Moreira (1998) e SAMAIN, Etienne (1998).

Movimento, Porto Alegre, v.12, n. 02, p. 223-239, maio/agosto de 2006. 
está recebendo obras para ampliação dessa dimensão) e o Grêmio Atlético Farroupilha (o Fantasma²), fundado em 21 de abril de 1926 com o estádio General Nicolau Fico onde pode receber cerca de 6.000 pessoas. As três equipes da cidade de Pelotas ao longo dos anos consolidaram sua tradição no futebol em âmbito estadual e nacional. G. E. Brasil, E. C. Pelotas e G. A. Farroupilha ostentam em suas galerias uma série de troféus de inúmeros torneios e campeonatos dentre os quais se destaca o título de campeão estadual, conquistado pelos três clubes em 1919, 1930 e 1935, respectivamente.

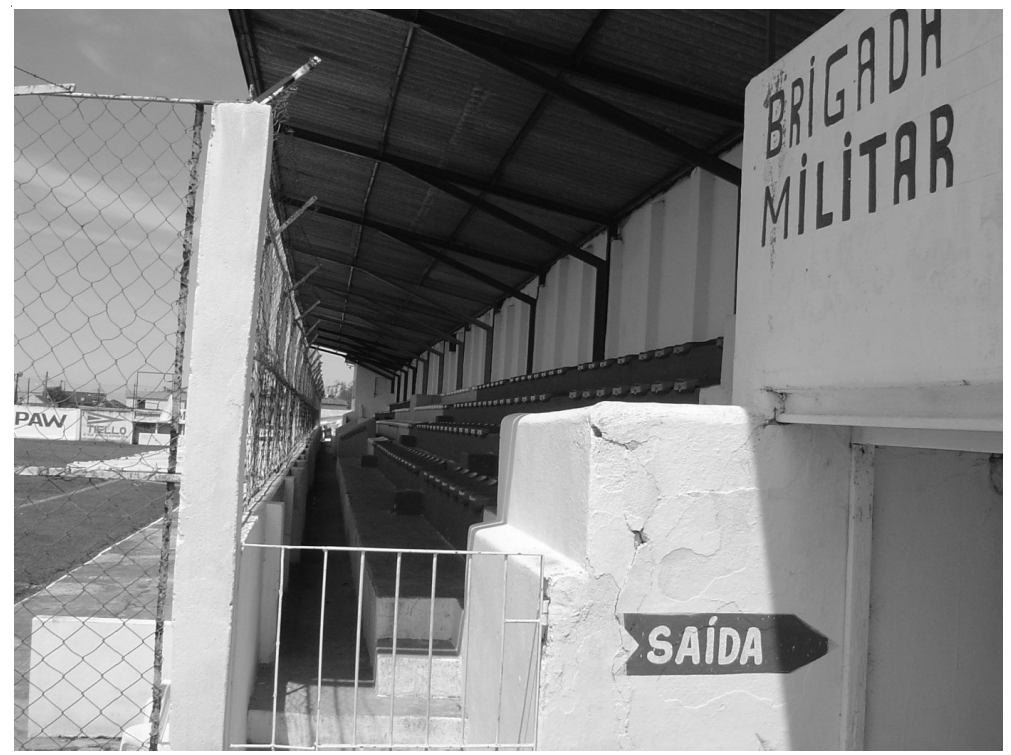

Figura 2: Pavilhão dos sócios no estádio General Nicolau Fico. (G. A. Farroupilha). Foto: Ricardo Tavares.

Os torcedores rubro-negros regozijam-se até hoje pelo fato do G. E. Brasil ter figurado entre os grandes clubes da primeira ${ }^{2}$ Fantasma ou fantasminha é o apelido pelo qual o Grêmio Atlético Farroupilha também é
conhecido, este apelido deve-se ao fato do clube ter sua sede e estádio situado no bairro
Fragata, próximo ao cemitério São Francisco de Paula, e também pela tradição de antiga-
mente dar sustos na dupla Gre-Nal.

Movimento, Porto Alegre, v.12, n. 02, p. 223-239, maio/agosto de 2006. 
divisão, tendo alcançado a terceira colocação no Campeonato Brasileiro de 1985, quando perdeu as semifinais para o Bangu do Rio de Janeiro. No ano de 2004 o clube foi campeão da cidade e recuperou sua hegemonia, sagrando-se campeão da segunda divisão do campeonato gaúcho, voltando assim, a partir de 2005, a pertencer novamente à elite do futebol gaúcho (primeira divisão).

Entre as virtudes do E. C. Pelotas destaca-se a constância da sua torcida no Estádio da Boca do Lobo. Durante três anos consecutivos $(2003,2002,2001)$ o clube apresentou a maior média de público pagante no campeonato gaúcho, dentre os clubes do interior do estado $^{3}$. Recentemente o clube disputou competições de âmbito nacional, como a Copa Sul-Minas (2002) e a Copa do Brasil (2003). Apesar da fidelidade da torcida e de possuir uma boa infra-estrutura, em 2004 o clube foi rebaixado para segunda divisão do campeonato gaúcho e ainda não conseguiu retornar à primeira.

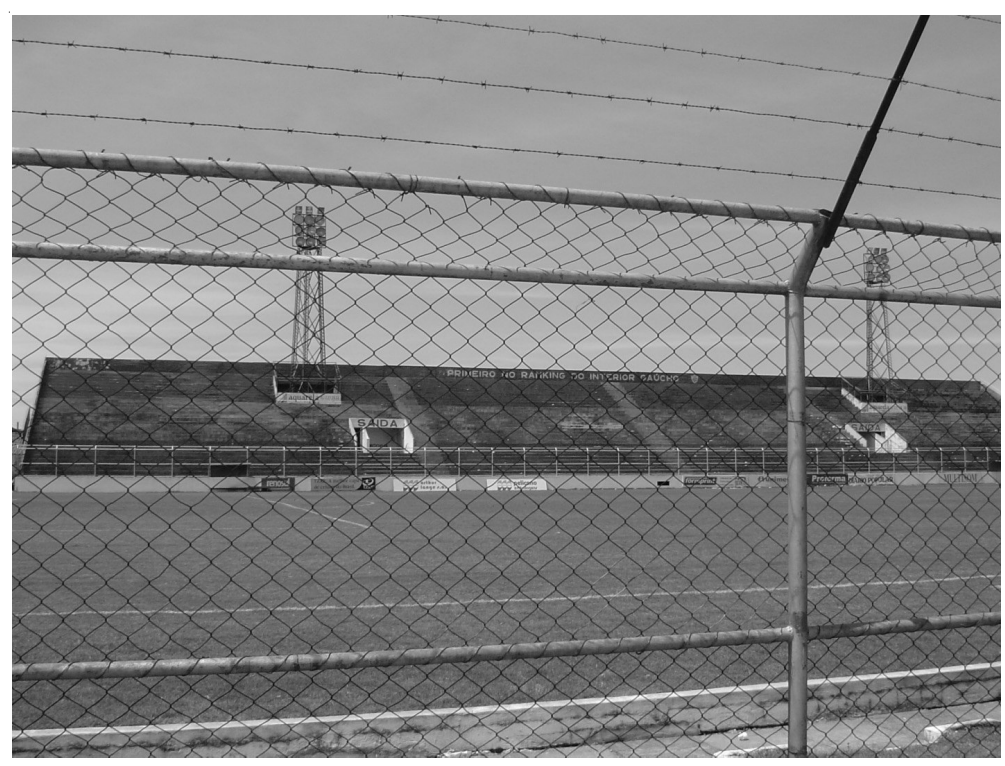

Figura 3: Estádio Boca do Lobo (E. C. Pelotas). Foto: Ricardo Tavares.

${ }^{3}$ Dados retirados do site do E. C. Pelotas, disponível em: www.ecpelotas.com.br.

Movimento, Porto Alegre, v.12, n. 02, p. 223-239, maio/agosto de 2006 
O G. A. Farroupilha atravessa uma situação inversa à do E. C. Pelotas, após figurar durante anos na terceira divisão (hoje instinta) do campeonato gaúcho conseguiu ascender para a segunda divisão e em 2004 tornou-se novamente um dos clubes que faz parte da primeira divisão do campeonato gaúcho, onde se mantém atualmente.

Esses três clubes profissionais não são os únicos clubes de futebol da cidade, espalhados pelos diferentes pontos da cidade. Existe uma quantidade enorme de clubes amadores, alguns mais tradicionais, remanescentes dos anos 20, 30 e 40 e outros mais recentes, dos anos 70, 80, 90 formando aquilo que podemos chamar de uma cultura futebolística da cidade ${ }^{4}$.

Essa cultura futebolística, resultante de um século de futebol, que caracteriza a cidade de Pelotas constitui, nos pelotenses, uma subjetividade futebolística bastante singular. No meio futebolístico circulam informações apontando Pelotas como a única cidade do Estado em que a dupla Gre-Nal (Grêmio e Internacional) não aparece em primeiro lugar quanto ao número de torcedores.

A tradição do futebol somado com a forte rivalidade existente entre G. E. Brasil, E. C. Pelotas e G. A. Farroupilha introjetam nos amantes do futebol um sentimento clubista citadino que é repassado de geração para geração e mantém-se mesmo quando os clubes não estão em suas melhores fases ${ }^{5}$.

\section{Estatuto de defesa do torcedor}

O Estatuto de Defesa do Torcedor é dispositivo legal, lei $n^{\circ}$ 10671, de 15 de maio de 2003, dividido em 12 capítulos e 45 artigos

${ }^{4} \mathrm{Em}$ outro estudo que realizamos especificamente sobre os clubes amadores na cidade encontramos o Sport Club Campônes que é remanescente de 1910 e ainda está em atividade. Ver: RIGO. L. C. et al. Memórias de Corpos Esportivizados, mimeo, 2004.

${ }^{5}$ Sobre a história do futebol em Pelotas, sua constituição, os principais clubes, jogadores que ficaram conhecidos e o destaque que ele ocupa dentro da historiografia do futebol gaúcho e brasileiro consultar: RIGO, Luiz Carlos. Memórias de um futebol de fronteira, 2004 e ALVES, Eliseu Mello, 1984.

Movimento, Porto Alegre, v.12, n. 02, p. 223-239, maio/agosto de 2006. 
que foi elaborado sob a coordenação do Ministro do Esporte Agnelo Santos Queiroz com a participação direta de Márcio Fontes de Almeida, Marcio Thomaz Bastos, Álvaro Augusto Ribeiro Costa e foi sancionado pelo presidente Luiz Inácio Lula da Silva ${ }^{6}$.

Apesar das suas disposições não se restringirem ao futebol entre as atribuições conferidas ao EDT, destaca-se o combate e a prevenção à violência nos estádios, a garantia de alguns direitos do consumidor (torcedor) ${ }^{7}$ e a tentativa de assegurar uma maior transparência aos aspectos administrativos do futebol brasileiro.

Partindo da classificação feita por Luis Henrique de Toledo (2002) o qual divide os personagens do futebol em "profissionais, especialistas e torcedores", o EDT afeta de forma mais direta os torcedores, porém, como o próprio autor assinala, é importante a observação de que esta distinção de grupos envolvidos com o futebol é relativa, e há entre eles uma inter-relação permanente. Durante a entrevista que realizamos com um dos dirigentes do G. A. Farroupilha foram destacados aspectos dessa inter-relação:

\begin{abstract}
O torcedor é a chave de uma agremiação esportiva [...] aqui se trata com máximo de respeito e consideração todos que vêm ao nosso estádio, os senhores adentraram nele agora e viram a grande preocupação que está nos movendo, nos tocando, para que nós possamos receber esse público carinhosa e respeitosamente (entrevista com E. P. 2005).
\end{abstract}

$\mathrm{O}$ primeiro ponto analisado em nosso estudo se refere ao cumprimento ou não do artigo sétimo do EDT que trata da divulgação, durante o jogo, por intermédio do serviço de som e imagem dos estádios, da renda, arrecadação obtida pela venda dos ingres-

\footnotetext{
${ }^{6}$ Nomes que assinam o estatuto.

${ }^{7}$ Neste caso, o torcedor que freqüenta os estádios, é tratado por muitos, como apenas um mero consumidor, o que pode se comprovar na leitura de diversos artigos publicados $n$ internet a respeito das repercussões do estatuto na sociedade, como por exemplo, em NERY (2005).
}

Movimento, Porto Alegre, v.12, n. 02, p. 223-239, maio/agosto de 2006. 
sos, e do número de torcedores presentes em cada partida, (pagantes e não pagantes). Nos três estádios que visitamos constatamos que este artigo costuma não ser cumprido em nenhum deles, mesmo porque os clubes analisados não possuem serviço de som e nem placar eletrônico em seus estádios. Outro item relacionado à infraestrutura dos estádios observados é o que está disposto no artigo 22 do EDT e trata da numeração dos ingressos e a sua correspondência nas arquibancadas, nesse ponto também verificamos que os clubes da cidade não conseguiram ou não se preocuparam em se adequar a essa exigência do EDT. Nos estádios Boca do Lobo e Nicolau Fico, por exemplo, somente os lugares destinados aos sócios são numerados, já no estádio Bento Freitas não há sinais de numeração, nas arquibancadas e nem nos lugares destinados aos sócios.

Avaliando o capítulo VI do estatuto que trata do acesso e transporte do torcedor, percebemos que em Pelotas o transporte até o estádio deixa muito a desejar, em jogos com maiores públicos geralmente os ônibus encontram-se superlotados e os seus horários não são divulgados. Também é necessário ressaltar que nenhum dos estádios possui estacionamento exclusivo e compatível com o público, portanto aquele que utilizar como meio de transporte um veículo privado, estará sujeito a arranhões, arrombamentos e depredações.

Quanto às normas de higiene e qualidade das instalações sanitárias exigidas no estatuto, verificamos que em sua maior parte não estão cumpridas. O artigo 29 do estatuto cita que é direito do torcedor que os estádios possuam sanitários em número compatível com sua capacidade de público, em plenas condições de limpeza e funcionamento. Em nossa abordagem feita respectivamente em março e outubro de 2004, e fevereiro de 2005 constatamos que havia ineficiência nos três estádios, que apresentavam-se com dependências inacabadas, sem sanitários, com as paredes pichadas, áreas sem ventilação adequada, escuras e com odor extremamente desagradável. Na segunda visita que realizamos

Movimento, Porto Alegre, v.12, n. 02, p. 223-239, maio/agosto de 2006. 
verificamos apenas no estádio Bento Freitas alguma melhoria dos sanitários. Segundo o depoimento do dirigente do clube ela foi possível em função de parcerias estabelecidas com empresários locais. "Devemos a reforma dos nossos banheiros à iniciativa privada, sem ela não poderíamos ter feito isso, porque, infelizmente, a despesa é grande, e temos outras prioridades" (Entrevista N. M., 2005).

No estádio da Boca do Lobo, na área destinada aos nãosócios, alguns sanitários parecem receber limpeza periódica. Mesmo assim, em outras dependências desse estádio observamos condições precárias e há necessidade de melhorias. Já no que se refere às condições dos sócios a realidade difere: nos três estádios o ambiente é limpo e bem iluminado, mantendo condições adequadas de higiene e conforto.

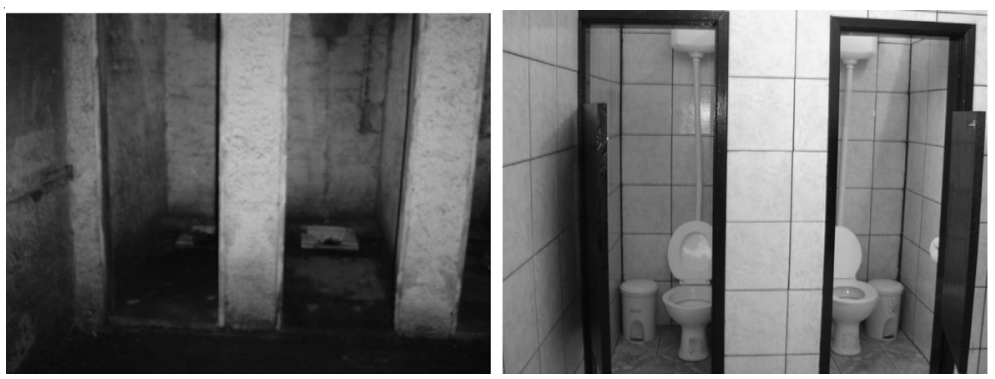

Figura 4: comparação do banheiro dos torcedores do estádio Bento Freitas, à esquerda a situação do banheiro em março de 2004 e à direita em outubro do mesmo ano. Foto: Ricardo Tavares.

Outra reclamação constante entre os torcedores, que costumamos ouvir nas ruas em dias de jogos, diz respeito aos preços dos ingressos, principalmente nas competições oficiais. Em Pelotas, assim como podemos perceber em outros locais de nosso país, os clubes vêm procurando executar promoções para atrair os torcedores, de forma que eles possam adquirir os ingressos para uma sequiência de jogos. Sobre as condições dos torcedores brasileiros, Mack (1980) destaca ser o poder aquisitivo pequeno e toda semana haver rodada pelos campeonatos, não levando em conta o Brasil ser um país em desenvolvimento.

Movimento, Porto Alegre, v.12, n. 02, p. 223-239, maio/agosto de 2006. 
Segundo o dirigente do E. C. Pelotas, muitas vezes o clube reduz o preço do ingresso a valores mais acessíveis do que os parâmetros estipulados para o campeonato, ressarcindo a Federação. No caso do G. E. Brasil, a direção oferece promoções de pacotes de vendas de ingresso, como foi, por exemplo, a promoção denominada de Sócio-Patrocinador ${ }^{8}$. No G. A. Farroupilha, E. P. (2005) informou-nos de que o clube trabalha com duas categorias diferentes para a arrecadação de renda contínua: os associados que pagam a metade do ingresso e têm acesso à arquibancada; e a modalidade da venda de cadeiras, pela qual o torcedor compra aquele espaço e está apto a freqüentar todos os jogos no Nicolau Fico, isento do valor do ingresso.

Quanto à distribuição dos locais de vendas de ingresso, a orientação do estatuto é de existir no mínimo cinco postos de vendas em diferentes partes da cidade, tendo em vista facilitar a aquisição dos mesmos. Em Pelotas é sabido que isto não ocorre, geralmente os clubes concentram a venda de ingressos em no máximo dois locais. A importância ou não de seguir esta orientação do estatuto deve ser analisada levaodo em conta que o seu não cumprimento prejudica os torcedores mais afastados do centro da cidade, os quais, quase sempre, são os de menor poder aquisitivo.

Sobre as insatisfações dos torcedores e sua relação com o clube, G. G. (2005) nos informou que o E. C. Pelotas disponibiliza de um processo de ouvidoria do torcedor. Já o G. A. Farroupilha, segundo E. P. (2005), conta com o auxílio da Brigada Militar para prestar esse serviço. Além de atender a uma das especificações do estatuto do torcedor, a ouvidoria, serve para estabelecer um canal de comunicação e aproximação entre clube e torcedor.

${ }^{8}$ Promoção onde o torcedor pagava determinada quantia em dinheiro mensalmente $e$ estava apto a assistir todas as partidas realizadas no estádio Bento Freitas. Ainda que não usufruísse nenhum outro benefício como alguma estrutura sócio-recreativa, a promoção foi muito divulgada e comentada por seus torcedores em 2004, seu ano de criação.

Movimento, Porto Alegre, v.12, n. 02, p. 223-239, maio/agosto de 2006. 
Nos estádios de Pelotas há também aqueles problemas corriqueiros dos estádios brasileiros, como, por exemplo, o preço dos lanches e das bebidas e a dificuldade para adquirí-los durante os 15 minutos de intervalo das partidas.

Por último, preocupamo-nos em analisar a segurança dos torcedores nos estádios e a violência, tema que assola a maioria dos estádios brasileiros e é bastante pertinente para o caso de Pelotas ${ }^{9}$. Nos artigos 13 e 39, prevê-se punição àqueles que transgredirem a ordem, ou incitarem a violência num raio de cinco mil metros ao redor da localidade do evento esportivo, e discorre sobre os cuidados relativos à segurança que deve haver, antes, durante e após a realização dos eventos esportivos. No caso da transgressão envolver torcedores a punição prevê o afastamento dos participantes das dependências do estádio por um período de três meses a um ano.

Em Pelotas observamos que, principalmente em dia de clássico, a situação da segurança e da violência continua a preocupar torcedores e clubes. Nas entrevistas realizadas tanto o dirigente do E. C. Pelotas, como o do G. E. Brasil comentaram que, em dia de jogos decisivos ou de clássico Bra-Pel, mesmo havendo um aumento do contingente de oficiais da Brigada Militar, os clubes estão aderindo a planos alternativos de segurança, como a contratação de empresas privadas desse ramo. Esse tipo de medida visa a estabelecer um estado de tranqüilidade maior tanto para o clube, como para os torcedores, evitando que os sentimentos de rivalidade típicos do futebol se transformem em violência.

Sobre a importância e os riscos que advêm da rivalidade no futebol Richard Giulianotti (2002) assinala que, se, por um lado à 9 Pelotas registra um histórico significativo de tensionamento e conflitos envolvendo os
clubes da cidade, um dos episódios mais traumatizantes dessa violência ocorreu dia 02/
10/2003. Nessa ocasião, após a final de um Bra-Pel, nas imediações do estádio Bento
Freitas um grupo de torcedores do G. E. Brasil espancou até a morte o empresário e
torcedor do E. C. Pelotas, Gilberto Bonow de 52 anos. (Jornal Diário Popular, 04/10/2003).

Movimento, Porto Alegre, v.12, n. 02, p. 223-239, maio/agosto de 2006. 
rivalidade age como um estímulo para criar uma atmosfera do jogo, acrescentado que "quanto mais intensa a 'atmosfera', mais aprazível o jogo" (p. 97), por outro lado o próprio autor adverte que nos casos em que há um "excesso de atmosfera" (p. 97), a balança tende para o outro lado e a disputa pode adquirir um estado venenoso ou diabólico.

No tocante à questão da violência nos estádios é importante observar que adentramos em um assunto que, certamente, extrapola as constatações relativas à implementação do EDT e ingressa-se em um outro ponto de discussão, no qual muitas perguntas estão ainda sem resposta. Como é o caso, por exemplo, de se diagnosticar com maior rigor até que ponto a violência nos estádios brasileiros são ocasionadas pelas torcidas organizadas, ou por torcedores individuais? Luiz Henrique de Toledo $(2000,1999,1996)$ concorda que parte da violência nos estádios pode estar relacionada às chamadas torcidas organizadas, porém discorda dos discursos que tendem a elegê-las como as únicas promotoras.

Sobre a atualidade e a complexidade envolvendo o tema da violência e das torcidas organizadas, Carlos Alberto Máximo Pimenta questiona se o fim das torcidas organizadas irá contribuir para a modernização do futebol e salienta que:

\footnotetext{
[...] a ritualização, a dramatização e a paixão, dentro do contexto futebolístico, afrouxam no torcedor seus freios racionais introjetados pelo modelo civilizador, deixando-o suscetivel a comportamentos inesperados e a violência independe da classe social, da cor da pele ou do poder econômico do agressor (PIMENTA, 1999, p. 143) ${ }^{10}$.
}

${ }^{10}$ Maiores considerações sobre a violência nos estádios de futebol e suas possíveis relações com as torcidas organizadas no futebol consultar: BUFORD, Bill. Entre os vândalos, 1992 e TOLEDO, Luis Henrique de. Lógicas no Futebol., 2002.

Movimento, Porto Alegre, v.12, n. 02, p. 223-239, maio/agosto de 2006. 


\section{Considerações finais}

Após a realização deste estudo, se por um lado parece claro e quase redundante afirmar que a elaboração do EDT consiste em um passo importante para o avanço do esporte brasileiro e mais ainda quando se trata do caso do nosso futebol, por outro lado é quase óbvio afirmar a mera promulgação do EDT não ser suficiente para trazer as melhoras que o esporte brasileiro tanto necessita. Nesse sentido acreditamos se tornar fundamental voltarmos a colocar em pauta o EDT, analisando os avanços, mas também os riscos e os desacertos nele contidos.

Publicado no mesmo ano em que o EDT entrou em vigor (2003), um artigo de André Schröder (2005) já se preocupou em fazer um balanço crítico do EDT, apontando nele algumas incongruências que, no nosso estudo, podemos averiguar de forma empírica junto à realidade dos clubes pelotenses.

Uma das principais impertinências apontada por André Schröder (2005), se refere a um certo eurocentrismo presente no EDT. O autor cita como um exemplo dessa cópia dos modelos europeus o artigo da numeração dos ingressos, colocando-o como algo descontextualizado e sem sentido: "a cultura do torcedor brasileiro não é igual à cultura do torcedor europeu. No Brasil, os torcedores assistem aos jogos de pé, pulando e se deslocando pelas arquibancadas". E, acrescenta o autor: "Essa medida irá tirar a liberdade que os torcedores têm de se movimentar na comemoração do gol, ou então de trocar de lugar quando seu time inverte o lado do campo que joga". Durante a nossa pesquisa observamos que nos três clubes de Pelotas este artigo vem sendo totalmente ignorado. Se isto não é de todo ruim, já que representa uma resistência espontânea dos clubes brasileiros, questionamos até que ponto a existência de artigos ignorados não compromete a credibilidade e a própria legitimidade do EDT.

Outra preocupação pertinente diz respeito aos riscos que as

Movimento, Porto Alegre, v.12, n. 02, p. 223-239, maio/agosto de 2006. 
alterações e modernizações dos estádios brasileiros possam contribuir para uma maior elitização do nosso futebol. Richard Giulianotti (2002) alerta-nos para o fato de que todo o processo de modernização ocorrido nos estádios europeus a partir dos anos 80 e 90, com a instalação de medidas de segurança, estacionamento, toaletes e quiosques de alimentação - medidas em muitos casos similares às que propõe o EDT - vieram acompanhadas do aumento dos preços dos ingressos, o que alterou o perfil dos torcedores causado uma elitização do futebol. Segundo ele "a partir de agora, cada vez mais é menos provável os maiores estádios receberem seu antigo público da classe operária para os principais jogos" (GIULIANOTTI, 2002, p. 108) ${ }^{11}$.

Durante as entrevistas realizadas com os dirigentes dos clubes observou-se certa confusão entre as disposições do Estatuto e o regulamento oficial da competição, no caso dos campeonatos organizados pela Federação Gaúcha de Futebol. Esta situação, a nosso ver, pode estar relacionada com a maneira um tanto generalista como vem sendo feita a divulgação do EDT, dificultando uma clareza maior sobre os mecanismos de fiscalização e implementação. Pelo menos no âmbito dos clubes de Pelotas foi o que encontramos. Segundo o projeto de lei aprovado, o EDT entraria em vigor em sua totalidade seis meses após sua data de publicação, ocorrida em 15 de maio de 2003.

Sabemos que a maioria dos episódios ocorridos nos estádios é mais um reflexo da sociedade do que simplesmente a falta de responsabilidade exclusiva dos clubes. Porém sabemos também que em muitos casos algumas medidas preventivas por parte dos responsáveis pela organização do espetáculo podem evitar trágicos acidentes e muitas cenas de violência. Nesse sentido consideramos que mais do que ocorreu durante a sua elaboração é impor-

${ }^{11}$ Bill Buford (1992) em seu clássico livro "Entre os vândalos: a multidão e a sedução da violência" é outro autor que analisa as transformações que ocorreram no futebol inglês em decorrência das mudanças dos estádios.

Movimento, Porto Alegre, v.12, n. 02, p. 223-239, maio/agosto de 2006. 
tante que a implementação do EDT aconteça conectada a realidade do mundo futebolístico brasileiro, respeitando as peculiaridades dos clubes, dos jogadores e dos torcedores. Realidade constituída por inúmeros defeitos, mas também por qualidades que são reconhecidas e invejadas pelo resto do mundo.

Por fim, cabe aqui um elogio às diretorias do G. E. Brasil, E. C. Pelotas e G. A. Farroupilha pelos cuidados com as condições dos gramados e pelos esforços que os três clubes vêm tentando fazer para melhorar as condições dos estádios. Cabe também agradecer e destacar a recepção e a acessibilidade que tivemos dos clubes e respectivos dirigentes, além de se mostrarem interessados no nosso estudo eles nos revelaram em seus depoimentos estarem empenhados na tentativa de por em prática o Estatuto de Defesa do Torcedor e esperam que a implementação do mesmo traga significativas melhorias para o futebol local.

Spectator's Statute of Defense: a Dialogue with
the Pelotense Soccer.
Abstract: This study has as objective analyses the
situation of the stadiums of professional soccer of
Pelotas, using as reference the Spectator's Statute
of Defense (SSD), with special attention to the
conditions of hygiene, safety, entrances and
transport. As methodology, besides documental
analysis of the SSD we realized visits to the
stadiums in three moments where we took
photographic registrations, as well as interviews
with one manager of each club: Grêmio Esportivo
Brasil, Esporte Clube Pelotas e Grêmio Atlético
Farroupilha. We verified that the attention dedicated
for press communication and controllers organs to
implementation of SSD is being less than occurs at
the moment of your publication.
Keywords: Soccer. Statute. Spectator.

Movimento, Porto Alegre, v.12, n. 02, p. 223-239, maio/agosto de 2006. 


\begin{abstract}
Estatuto de Defensa del Hincha: un diálogo con el fútbol Pelotense

Resumen: Este estudo objetiva analisar la situación de los estadios de fútbol de la ciudad de Pelotas, tomando como referencia el Estatuto de Defensa del Hincha (EDH), con atención especial para las condiciones de higiene, seguridad, ingreso y transporte. Como metodología, además del analisis documental del EDH realisamos visitas a los estadios en tres momentos con registros fotográticos y entrevistamos un dirigente de cada club: Gremio Desportivo Brasil, Esporte Club Pelotas y Gremio Atlético Farroupilha. Constatamos que la atención dedicada en la media y por los organos fiscalizadores a la implementación del EDH es menor de la que ocurrió en el momento de la publicación.

Palabras-clave: Fútbol. Estatuto. Hincha.
\end{abstract}

\title{
REFERÊNCIAS
}

ALVES, Eliseu Mello. O futebol em Pelotas, 1901 - 1940. Pelotas: Livraria Mundial, 1984.

BRASIL. Lei 10.671. Estatuto de Defesa do Torcedor, 2003.

BRASIL. Ministério do Esporte. Disponível em: <www.esporte.gov.br>. Acesso em: 17 ago. 2004.

BU FORD, Bill. Entre os Vândalos: a multidão e a sedução da violência. São Paulo: Companhia das Letras, 1992.

DIÁRIO POPULAR, Pelotas: 04 Out. 2003, Capa. Disponível em: $<$ www.diariopopular.com.br>. Acesso em: 15 dez. 2003.

ESPORTE Clube Pelotas. Disponível em: <www.ecpelotas.com.br>. Acesso em: 19 mar. 2004.

FELDMAN-BIANCO, Bele; LEITE, Mirian Moreira. Desafios da imagem: fotografia, iconografia e vídeo nas ciências sociais. Campinas: Papirus, 1998.

GIULIANOTTI, Richard. Sociologia do Futebol: dimensões históricas e socioculturais do esporte das multidões. São Paulo: Nova Alexandria, 2002.

MACK, R.C.V. Futebol Empresa a Nova Dimensão Para o Futebol Brasileiro. Rio de Janeiro: Palestra, 1980.

Movimento, Porto Alegre, v.12, n. 02, p. 223-239, maio/agosto de 2006. 
NERY, Daniel Christianini. Futebol e Política... Não se discute? Disponível em: $<$ www.revistaautor.com.br/artigos/2003/w24/dnn 24.shtml>. Acesso em: 12 jan. 2005. OS 500 MAIORES times do Brasil. Revista Placar, n.1127-A, 1997.

PIMENTA, Carlos Alberto Máximo. As transformações na estrutura do futebol brasileiro: o fim das Torcidas Organizadas nos estádios de futebol. In: COSTA, Márcia Regina da et al. (Org.). Futebol Espetáculo do Século. São Paulo: Musa 1999.

RIGO. L. C. et al. Memórias de Corpos Esportivizados: a natação feminina e o futebol infame, 2004. Mimeog.

RIGO, Luiz Carlos. Memórias de um futebol de fronteira. Pelotas: Editora Universitária, UFPel, 2004.

SAMAIN, Etienne. O fotográfico. São Paulo: Hucitec, 1998.

SCHRÖDER, André. Estatuto de Defesa do Torcedor gera polêmica. Disponível em: <http://paginas.terra.com.br/arte/359/48estatuto.htm>. Acesso em: 15 maio 2005.

TOLEDO, Luis Henrique de. A invenção do torcedor de futebol: disputas simbólicas pelos significados do torcer. In: COSTA, Márcia Regina da et al. (Org.). Futebol Espetáculo do Século. São Paulo: Musa, 1999.

Lógicas no futebol. São Paulo: Hucitec:Fapesp, 2002.

No País do Futebol. Rio de Janeiro: Jorge Zahar, 2000

Torcidas organizadas de futebol. Campinas: Autores Associados:ANPOCS, 1996.

TRIVIÑOS, Augusto Nibaldo da Silva. Introdução à pesquisa em ciências sociais: a pesquisa qualitativa em educação. São Paulo: Atlas, 1987. 